\section{Evaluation of the animal welfare during religious slaughtering}

\author{
Roberta Barrasso, ${ }^{1}$ Elisabetta Bonerba, ${ }^{1}$ \\ Edmondo Ceci, ${ }^{1}$ Rocco Roma, ${ }^{2}$ \\ Antonio Alò, ${ }^{1}$ Anna Mottola, ${ }^{1}$ \\ Patrizia Marchetti, ${ }^{1}$ \\ Gaetano Vitale Celano, ${ }^{1}$ \\ Giancarlo Bozzo ${ }^{1}$
}

${ }^{1}$ Department of Veterinary Medicine, ${ }^{2}$ Department of Agricultural and Environmental Science - University of Bari "Aldo Moro", Bari, Italy

\section{Abstract}

Plasma cortisol and its metabolites are physiological indicators for stress assessment and slaughtering method may affect their levels, playing an important role in the correct acidification of meat. The aim of the study was to determine and compare plasma cortisol values in animals slaughtered using traditional procedures, which include stunning (using captive bolt pistol), with those in animals slaughtered using Halal method, which does not involve stunning. The study was carried out on a total of 60 Charolais male beef cattle of eight months of age, bred in free paddock outdoors. The animals were divided into two experimental groups, each consisting of 30 individuals, on the basis of the slaughtering method, i.e. traditional or Halal, to verify the whole production chain and to ensure that the product conformed to Muslim rules. Plasma cortisol levels (detected by Elisa test) were evaluated at two different times of animal productive life: on the farm, one week before slaughter (T0) and during bleeding (T1). The 30 calves slaughtered after stunning showed plasma cortisol values of $4.06 \pm 1.94$ and $43.72 \pm 12.09 \mathrm{nmol} / \mathrm{L}$, respectively on the farm and during exsanguination. Conversely, the average values found in the 30 calves subjected to ritual slaughter were $3.26 \pm 1.01$ and $88.81 \pm 41.02 \mathrm{nmol} / \mathrm{L}$. The study demonstrated that throughout the animal's productive life (from pasture to slaughter) the greatest variation between slaughter with and without stunning was observed during bleeding.

\section{Introduction}

Ritual slaughter often comes under discussion as it is carried out without any kind of stunning. Typical of cultures such as Judaism and Islam, it is performed in dero- gation from the provisions of Council Regulation (EC) $N^{\circ} 1099 / 2009$ on the protection of animals at the time of killing, following precise rules prescribed by the religious rite (blessings or invocations), which characterize its sacredness (Italian National Bioethics Committee, 2003).

The word Halal is an Arabic term that means anything or act that is permissible in accordance with Sharia law. In order to be acceptable for Muslim consumption, slaughter must meet certain conditions specified in the Qur'an and Hadith (Fuseini et al., 2016). At a basic level, Halal slaughter requires animals to have a pre-slaughter rest, and to be well fed and well looked after at the time of slaughter (Rahman, 2017). They must be alive at the point of slaughter and, if pre-slaughter stunning is performed, this must necessarily be reversible and must not result in the death of the animal before slaughter. Indeed, if not slaughtered, stunned animals must be able to make a full recovery (Fuseini et al., 2016). The personperforming animal bleeding must have attained the age of discretion and must be mentally stable. The slaughterer should preferably be Muslim although the Qur'an allows Muslims to consume meat slaughtered by Christians and Jews (Qur'an, 1983). The slaughterer must pronounce the name of Allah during the slaughter of each animal, which should preferably face Qibla (Qur'an, 1983). Before the throat is cut, the animal should be securely restrained, particularly the head and neck. All efforts should be made to slaughter the animal with one stroke using a very sharp knife and without leaving any blemishes or damage (Rahman, 2017). In fact, slaughter must be performed with a single movement of the knife, which must be sharpened out of sight of the animal, which should be slaughtered out of sight of other animals and shielded from the view of blood (Fuseini et al., 2016). Slaughter shall be carried out from the front (towards the chest) and not from behind (towards the back) and the head should not be severed from the neck during slaughter (Riaz, 2004). The act of slaughter must begin with an incision on the animal's neck just below the glottis; the animal's trachea and oesophagus must be severed, the spinal cord should not be cut, and the head should not be completely severed, as this would induce immediate and massive haemorrhage (Fuseini et al., 2016). Finally, the carcass may not be processed, e.g. skinning or cutting off the hocks, before the animal is completely dead (Riaz, 2004).

The word Shechitàh is only used to describe the method of slaughtering used according to Jewish rules, which include precise precepts to define kosher animals
Correspondence: Roberta Barrasso, Department of Veterinary Medicine, University of Bari "Aldo Moro".

Strada Provinciale per Casamassima km 3, 70010 Valenzano (BA), Italy.

Tel: +39 080.5443851 - Fax: +39 080.5443851.

E-mail: roberta.barrasso@uniba.it

Key words: Animal welfare, Cortisol, Halal slaughter, Stunning.

Acknowledgments: The authors thank Stefano Sportelli for providing invaluable technical assistance in the laboratory.

Contributions: $\mathrm{GB}, \mathrm{RB}$ and $\mathrm{EC}$ designed the experiment; RB, EB and EC performed the experimental procedures; $\mathrm{RB}$ and RR conducted all statistical analysis. All authors contributed writing the paper.

Conflict of interests: The authors declare no potential conflict of interests.

Funding: None.

Availability of data and materials: The data that support the findings of this study are available from the corresponding author upon reasonable request.

Ethics approval and consent to participate: This research was conducted in accordance with all relevant guidelines and procedures.

Consent for publication: The manuscript does not contain any individual person's data in any form.

Received for publication: 11 July 2019.

Revision received: 2 December 2019.

Accepted for publication: 12 December 2019.

This work is licensed under a Creative Commons Attribution-NonCommercial 4.0 International License (CC BY-NC 4.0).

(C) Copyright: the Author(s), 2020

Licensee PAGEPress, Italy

Italian Journal of Food Safety 2020; 9:8387 doi:10.4081/ijfs.2020.8387

and to select those suitable for religious slaughter, even during the breeding phase (Farouk et al., 2014). Acceptable animals are slaughtered by a specially trained religious slaughter-man (shochet) using a special knife called chalef (Regenstein et al., 2003). The cutting procedure, capable of causing a quick drop in brain blood pressure, rapid exsanguination of the animal and loss of consciousness, must be performed with a back-and-forth motion and it renders the animal insensitive to pain (Rosen et al., 2004). When bleeding is finished, a postprocedure inspection follows, in which the animal is checked for the presence of 
lesions, especially in the lungs and liver. According to the number and type of these pulmonary and hepatic injuries, the carcasses will then be classified as chalak (or glatt), kosher and terif (Mast et al., 1983). After organ inspection, some portions of fat and organs such as the kidneys, the intestines and the sciatic nerve, are removed through a process called nikkur. All large arteries and veins, as well as any bruised meat or coagulated blood, are also removed because the blood is not considered edible. At the end of this selection, the meat is purged of all remaining blood through the koshering process (Farouk et al., 2014).

There are many similarities in the principles and practice of Halal and Kosher slaughters (Gregory, 2007), though also many differences. Indeed, during Kosher pre-slaughter, the animal must be alive and conscious, while the Halal rite only requires the animal to be alive. Any form of stunning that renders the animal insensible to pain prior to slaughter is not acceptable for Kosher, while for Halal, non-stunning is preferred, but reversible forms of stunning are widely accepted and practised. The Halal method also tolerates post-slaughter stunning, so as to prevent uncontrolled movements after animal exsanguination. The Jewish religion requires a special knife (chalef) for each species of animal, but blessing is not required for each animal. By contrast, for Islam, there is no special knife and it can be used for different species, but blessing is required for each animal. Although in both religious rites the cut must be performed with a single movement, even a single mistake during kosher slaughtering means the meat is regarded as unfit for human consumption, which is not the case in Halal slaughter. Finally, one last important difference is that for Jewish religion certain parts of the carcass cannot be eaten, while all edible parts of the carcass are considered Halal (Regenstein et al., 2003). Furthermore, the global volume and value of trade in Halal and Kosher meat is vast and has especially increased after the rise in the number of Islamic communities around the world (Lada et al., 2009). The global and European market for Halal food is estimated to be worth around 547 and 77 billion dollars per year, respectively (Lever et al., 2010).

Plasma cortisol and its metabolites are physiological indicators for stress assessment (Manteca, 2009) and the slaughter method used may affect the levels of stress indicators, playing an important role in the correct acidification of the meat (Nakyinsige et al., 2014). The pattern of plasma cortisol, measured in order to monitor stress in beef cattle slaughtered accord- ing to the rules imposed by the religious Jewish rite (Farouk et al., 2014), revealed significant changes particularly during bleeding, when compared to traditional slaughter. In agreement with a previous study (Bozzo et al., 2018), among the parameters used as stress indicators, plasma cortisol was the most useful, showing a statistically significant variation. The animals selected for kosher slaughtering showed lower levels of cortisol before and after transportation to the slaughterhouse, likely because their more docile temperament was the rationale for their selection by the Rabbis (Bozzo et al., 2018). Therefore, plasma cortisol levels increased considerably at the exsanguination phase in these animals, as they were not stunned and were restrained using a rotary pen (Ceci et al., 2017; Bozzo et al., 2018).

The aim of the study was to determine and compare plasma cortisol values in animals slaughtered using traditional procedures, which include stunning (using a captive bolt pistol), with those of Halal-slaughtered animals, which does not involve stunning (as mentioned in the holy Qur'an). Since animals are often handled roughly before and during transportation and given that transportation can cause injuries and fatigue to animals (Rahman, 2017), regardless of the slaughter method, we only monitored two times, i.e. pasture and bleeding. Furthermore, for this study we used the same experimental conditions applied in a previous study (Bozzo et al., 2018) to evaluate the differences between the two religious slaughtering procedures, Halal and Kosher.

\section{Materials and Methods}

\section{Ethical statement}

The experimental procedures were approved by the ethical committee of the Department of Veterinary Medicine at Bari University in Italy (Protocol no: 1235/18 17 May 2018).

\section{Sampling protocol}

The study, resulting from a partnership between the Food Safety Section of the Department of veterinary medicine at Bari University and a slaughterhouse in the Apulia region (Southern Italy), was conducted between March and May 2018. The study was carried out on a total of 60 Charolais male beef cattle of eight months of age, bred in the same free paddock outdoors. The transport took place on two consecutive days, during the same time of day and had the same duration in the two groups (about $45 \mathrm{~min}$ ). After transport, all the animals arrived at the same slaughtering establishment, where they were kept in the lairage facilities, for about 30-45 min, until slaughter. The animals were divided into two experimental groups, each consisting of 30 individuals, to verify the whole production chain and to ensure that the product conformed to Muslim rules. Thirty animals (group A) were selected by the responsible of the Muslim religious community and were slaughtered on the day after the animals slaughtered with the conventional procedure, at the exact same time of day.

In agreement with Regenstein et al. (2003) and Farouk et al. (2014), a Muslim or a practicing Jew (follower of Judaism) or Christian performed the Halal slaughtering. At the slaughterhouse, the authorized slaughter-men restrained the animals in a full inversion rotary pen. After this step, the animals were slaughtered by a perfectly clean incision, using a knife through the structures at the front of the neck: trachea, oesophagus, carotid arteries and jugular veins. In this study, the cattle were slaughtered using a conventional low neck cut (between the second and the fourth cervical vertebra), although the exact position on the neck is not specified in the Qur'an. Conversely, the other 30 animals (group B) were slaughtered after stunning by captive bolt gun, which causes immediate loss of consciousness, making the animals insensible to pain until death occurs due to exsanguination, as required by Council Regulation (EC) $N^{\circ} 1099 / 2009$ on the protection of animals at the time of killing. These 30 calves were from the same farm as the animals slaughtered by the Halal rite and were selected at random by the operators. Plasma cortisol levels were evaluated at two different stages in the animal's productive life: on the farm, one week before slaughter (time 0 ) and during bleeding (time 1). Blood samples of time 0 were collected from the jugular vein, both at 6:00 a.m. to exclude a circadian variation. In time 1 , the blood samples were collected during the exsanguination phase, which was carried out $30 \mathrm{~min}$ after the animal discharge. The blood samples were collected in vacutainer test tubes containing ethylenediaminotetracetic-acid (EDTA) and stored in ice at $0^{\circ} \mathrm{C}$ for no longer than $60 \mathrm{~min}$, avoiding freezing, before being transferred to the reference laboratory.

\section{Elisa test}

Plasma cortisol was determined as described in a previous study (Ceci et al., 2017). Briefly, the cortisol ELISA immunoassay test (Bovine Cortisol ELISA 
Kit; My-Bio-Source, San Diego, CA, USA) was used following the manufacturer's guidelines.

All reagents were kept at room temperature $\left(25-28^{\circ} \mathrm{C}\right)$ for $30-40 \mathrm{~min}$ before being reconstituted. Enzyme conjugate was stored at $-20{ }^{\circ} \mathrm{C}$ until use. Highly concentrated samples were diluted with sample diluent (e.g. 1:5 or $1: 10$ ) to obtain a readable range on the curve. In the first step, $50 \mu \mathrm{L}$ of standard was added to each standard well, 50 $\mu \mathrm{L}$ of plasma to each sample well and $50 \mu \mathrm{L}$ of sample diluent to each blank/control well. Standards, samples and diluent were added in duplicate to the plate. In the second step, $100 \mu \mathrm{L}$ of HRP\% (Horseradish Peroxidase) conjugate reagent was added to each well and incubated for $60 \mathrm{~min}$ at 37 ${ }^{\circ} \mathrm{C}$. In the third step, the plate was rinsed 4 times with a wash solution $(250-300 \mu \mathrm{L}$ per well) and then residual liquids were carefully removed. In the fourth step, $100 \mu \mathrm{L}$ of TMB (Tetra-Methyl-Benzidine) colour reagent was added to each well and the plate was incubated for $30 \mathrm{~min}$ at $18-25^{\circ} \mathrm{C}$ without shaking. The reaction was stopped by adding $100 \mu \mathrm{L}$ of $\mathrm{H}_{2} \mathrm{SO}_{4} 1 \mathrm{M}$ to each well and mixing gently for 1-2 min. Shortly after stopping the reaction, the optical density (OD) of each was determined using a micro plate reader with a wavelength of $450 \mathrm{~nm}$, $540 \mathrm{~nm}$ or $570 \mathrm{~nm}$. The mean of the readings of duplicates for each standard and sample was calculated, and the average OD of the blank was subtracted. A standard curve was created using a computer software capable of generating a four-parameter logistic (4-PL) curve-fit.

The minimum detectable dose of bovine cortisol (sensitivity) was $\geq 0.049 \mathrm{ng} / \mathrm{mL}$. The detection range was $0.049-200 \mathrm{ng} / \mathrm{mL}$. No significant cross reactivity or interference between bovine cortisol and analogues was observed. Intra-Assay Precision was $<8 \%$. Inter-Assay Precision was $<10 \%$ (manufactured in an ISO 13485:2003 and EN ISO 13485:2012 Certified Laboratory).

\section{Statistical analysis}

A statistical descriptive analysis based on central tendency and concentration indexes was carried out for the two groups of animals to provide a framework of the changes in plasma cortisol concentration on the farm and during bleeding. Moreover, the increasing rates from pasture to exsanguination were calculated, starting from an observation of the different cortisol concentration tendencies between the two groups of animals. The mean values of the two groups of animals and of the stress parameter monitored in this study were compared by oneway analysis of variance.

\section{Results}

Mean values, standard deviation and significance of the differences in plasma cortisol are shown in Table 1. The results revealed that cortisol was lower in group A than in group $\mathrm{B}$ in time 0 (F: 4.026; $\mathrm{P}=0.049$ ); on the other hand, cortisol levels were much higher in animals slaughtered by Muslim rite (group A) than in group B (F: 33.354; $\mathrm{P}=0.000)$ during bleeding. These data showed the greatest variation between farm (time 0) and exsanguination phase (time 1) in Halal-slaughtered animals, being 27.52 times higher, compared with those slaughtered by a traditional procedure, which had an average increase of 12.85 times (Table 2).

\section{Discussion}

In this study, we evaluated the stress to which the animal is submitted on the farm and during slaughtering by quantifying an objective indicator of stress, i.e. plasma cortisol, comparing traditional slaughter to the procedures required by the religious Islamic rite. Given that Mormède et al. (2007), showed a range of baseline cortisol values between zero and around $20 \mathrm{ng} / \mathrm{mL}$, with a mean lower than $5-10 \mathrm{ng} / \mathrm{mL}$, the average plasma cortisol values observed in this study were lower than those reported in the literature but very similar to the values reported in our previous work (Bozzo et al., 2018).

Plasma cortisol showed significant changes between the two times considered, i.e., during pasture (time 0) and during bleeding (time 1). The differences in the values detected on the farm were predictable due to the choice of the most docile and gentle animals by the responsible of the Muslim religious community (Farouk et al., 2014; Bozzo et al., 2018). On the other hand, plasma cortisol levels immediately after exsanguination (time 1) were much higher in the Halal-slaughtered animals than in those slaughtered after traditional stunning.

Also, the study which we used as our starting point (Bozzo et al., 2018) to compare Halal and Kosher rites, showed the greatest variation in plasma cortisol levels

Table 1. Mean values (M), Standard Deviation (SD) and Significance Level (P) between groups. The values are expressed in $\mathrm{nmol} / \mathrm{L}$.

\begin{tabular}{lcc} 
Plasma cortisol & $\begin{array}{c}\text { Cattle farm } \\
\text { (time } \mathbf{~})\end{array}$ & $\begin{array}{c}\text { Exsanguination } \\
\text { (time 1) }\end{array}$ \\
Religious Muslim rite & 3.26 & 88.81 \\
M & 1.01 & 41.02 \\
SD & & \\
Traditional slaughter & 4.06 & 43.72 \\
M & 1.94 & 12.09 \\
SD & 0.049 & 0.000 \\
\hline Between groups, P & & \\
\hline
\end{tabular}

Statistical significance: $\mathrm{P}<0.05$.

Table 2. Mean values (M), Standard Deviation (SD) and Standard Error (SE) of the increases between the two times. $M$ from time 0 to time 1 expresses the difference between the parameter recorded in time 1 and 0 , divided by the level found in time 0 . The values are expressed in $\mathrm{nmol} / \mathrm{L}$.

\begin{tabular}{lc} 
Plasma cortisol & From time 0 to time 1 \\
Religious Muslim rite & \\
M & 27.52 \\
SD & 11.91 \\
SE & 2.175 \\
Traditional slaughter & \\
M & 12.85 \\
SD & 8.50 \\
SE & 1.552 \\
\hline Total sample & \\
M & 20.18 \\
SD & 12.65 \\
SE & 1.633 \\
\hline
\end{tabular}

Statistical significance: $\mathrm{P}<0.05$. 
during bleeding. The same trend was observed between the animals slaughtered by the Kosher method and those slaughtered after stunning by captive bolt gun (F: 16.021; $\mathrm{P}=0.000$ ), although the Fisher $\mathrm{F}$ was almost half of the value recorded in this study (F: 33.354; $\mathrm{P}=0.000$ ). Moreover, the means of the increases between the two times during religious slaughter were similar in both studies $(25.51 \mathrm{nmol} / \mathrm{L}$ in the religious Jewish rite and $27.52 \mathrm{nmol} / \mathrm{L}$ in the religious Muslim rite) and overlapped in traditional procedures $(12.53 \mathrm{nmol} / 1$ in the previous study and $12.85 \mathrm{nmol} / \mathrm{L}$ in the latest one). These data (Table 2) could be explained whereas the Jewish slaughtering involves much more restrictive procedures than those observed during the Islamic rite (Farouk et al., 2014). As can be seen from Table 1, the average plasma cortisol values increase more than 10 times between the breeding and the exsanguination phases in animals slaughtered traditionally (from 4.06 to $43.72 \mathrm{nmol} / \mathrm{L}$ ), while they increase almost 30 times in those slaughtered following the religious Halal rite (from 3.26 to $88.81 \mathrm{nmol} / \mathrm{L}$ ). On the other hand, in the previous study on the Kosher rite (Bozzo et al., 2018), the growth rate between the two phases was about 23 times (from 2.96 to $68.70 \mathrm{nmol} / \mathrm{L}$ ). Furthermore, one of the main differences between the two methods of slaughter regards the knife used: Jewish precepts require the slaughtering knife (chalef) to be at least twice the neck width and perfectly sharp so as to ensure a single cut (Bozzo et al., 2017). Consequently, as indicated by some authors (Farouk et al., 2016), to achieve similar results these strict standards also need to be introduced into Halal procedures. For this reason, using the high neck cut (first cervical vertebra) instead of the conventional low neck cut (from second to fourth cervical vertebrae), ensured faster collapse of the animals and improved bleeding efficiency by reducing the frequency of false aneurysm formation and the early arrest of blood flow (Gibson et al., 2015).

Regarding the slaughtering procedures, in a previous study conducted by Dunn (1990), the cortisol levels of the cattle subjected to religious slaughtering in the rotary Weinberg pen were significantly higher than those of cattle slaughtered in the pen approved by the American Society for the Prevention of Cruelty to Animals (ASPCA), where the animals were upright (Grandin, 2010). On the other hand, rotating restraint boxes are preferred by some slaughter-men to give easier access to the animal's neck (Farouk et al., 2016). Because of the potential pain that could occur during the restriction process prior to slaughter, upright slaughter of the animals should preferably replace the rotary pen as a means of restraint (Farouk et al., 2016). Furthermore, during slaughter without prior stunning, complete immobilization of the head is absolutely necessary, even though the head holder causes more stress than body restraint (Grandin, 1992). Holding an animal too tightly causes it stress and can cause bruising in the meat (World Organization of Animal Health, 2013). Moreover, excessive stress to the body seemed to increase blood splash and reduce bleeding (Grandin, 1992). Many researchers (Gregory, 2008; Nakyinsige et al., 2014) reported a correlation between meat quality and blood, showing the need to remove more blood as fast as possible in order to extend the shelf life of the meat and to provide safer meat for human consumption. The study confirms what was already showed by Önenç and Kaya (2004), who claimed that slaughtering method affects plasma cortisol levels, which play a central role in meat acidification. Moreover, during stressful situations, the secretion of glucocorticoids stimulates hepatic glycogenolysis, leading to an increase in glucose levels (Knowles and Warriss, 2000; Pollard et al., 2002).

\section{Conclusions}

A survey of a small number of Halal consumers in the USA indicated an increased desire for better animal welfare in the production systems (Pufpaff, 2014). The Islamic ethical system takes the relationship between humans and other animal species quite seriously and argues that animals have feelings and interests of their own, of their own. Indeed, they have the have the right to be treated with kindness, respect and consideration (Farouk et al., 2014). Therefore, to achieve this goal, stunning should be introduced during religious slaughtering. In agreement with Islamic principles, the stunning method that may be acceptable and considered humane must not kill the animal, but only temporarily render it unconscious (reversible) in order to minimise the pain and distress caused by the act of slaughter. Although not all the Islamic community allows the introduction of stunning during slaughter, there are procedures that could be accepted, according to the precepts of the Qur'an. To reduce the stress of the animal not subjected to stunning, the following arrangements could be introduced: (i) using an ASPCA pen for animal restraint at the time of slaughtering, which keeps the animals in a natural position to prevent their excessive movement inside the restraint pen and to avoid repercussions related to reduced bleeding, (ii) employing a proper knife, with similar characteristics to that used during Kosher slaughter since animal welfare is affected by the size of the knife. Finally, (iii) cutting the neck at the level of the first cervical vertebra, so that death occurs earlier. All these procedures could improve animal welfare conditions at the slaughterhouse, increase meat quality and, importantly, are respectful of the Islamic religion. These measures may also be interpreted as a first step towards a point of balance between devotion to one's religion and respect for animal welfare.

\section{References}

Bozzo G, Barrasso R, Marchetti P, Roma R, Samoilis G, Tantillo G, Ceci E, 2018. Analysis of stress indicators for evaluation of animal welfare and meat quality in traditional and Jewish slaughtering. Animals 8:43.

Bozzo G, Di Pinto A, Bonerba E, Ceci E, Mottola A, Roma R, Capozza P, Samoilis G, Tantillo G, Celano GV, 2017. Kosher slaughter paradigms: Evaluation of slaughterhouse inspection procedures. Meat Sci 128:30-3.

Ceci E, Marchetti P, Samoilis G, Sportelli S, Roma R, Barrasso R, Tantillo G, Bozzo $\mathrm{G}$, 2017. Determination of plasmatic cortisol for evaluation of animal welfare during slaughter. Ital J Food Saf 6:1346.

Council regulation (EC) 1099/2009 of 24 September 2009 on protection of animals at the time of killing. Available online: https://eur-lex.europa.eu/legalcontent/EN/TXT/? uri=celex:32009 R1099 (accessed on 18 November 2009).

Dunn CS, 1990. Stress reactions of cattle undergoing ritual slaughter using two methods of restraint. Vet Rec 126:5225.

Farouk MM, Al-Mazeedi HM, Sabow AB, Bekhit AED, Adeyemi KD, Sazili AQ, Ghani A, 2014. Halal and kosher slaughter methods and meat quality: A review. Meat Sci 98:505-19.

Farouk MM, Pufpaff KM, Amir M, 2016. Industrial halal meat production and meat animal welfare: A review. Meat Sci 120:60-70.

Fuseini A, Knowles TG, Hadley PJ, Wotton SB, 2016. Halal stunning and slaughter: Criteria for the assessment of dead animals. Meat Sci 119:132-7.

Grandin T, 2010. Auditing animal welfare at slaughter plants. Meat Sci 86:56-65.

Grandin T, 1992. Observations of cattle restraint devices for stunning \& slaugh- 
tering. Anim Welf 1:85-91.

Gregory NG, 2007. Animal welfare and meat production (2nd ed.). Wallingford, UK: CABI Publishing, 213-226.

Gregory NG, 2008. Animal welfare at markets and during transport and slaughter. Meat Sci 80:2-11.

Gregory NG, Schuster P, Mirabito L, Kolesar R, McManus T, 2012. Arrested blood flow during false aneurysm formation in the carotid arteries of cattle slaughtered with \& without stunning. Meat Sci 90:368-72.

Italian National Bioethics Committee, 2003. Macellazioni Rituali e Sofferenza Animale; Italian National Bioethics Committee: Roma, Italy. pp. 91-96.

Knowles TG, Warriss PD, 2000. Stress physiology of animals during transport. In Livestock Handling and Transport; Grandin, T., Ed.; CABI Publishing: Wallingford, UK, pp. 385-408.

Lada S, Harvey TG, Amin H, 2009. Predicting intention to choose halal products using theory of reasoned action. Int J Islam Middle East Finance Manag 2:66-76.

Lever J, Puig della Bellacasa M, Miele M, Higgin M, 2010. From the slaughterhouse to the consumer: Transparency and information in the distribution of halal and kosher meat. Dialrel Report n.
43. Available at: http://orca.cf. ac.uk/20492/1/Dialrel_report_43.pdf.

Manteca X, 2009. Conceptos generales de bienestar animal. In Etología Veterinaria; Manteca, X., Ed.; Multimédica Ediciones Veterinarias: Barcelona, Spain. pp. 225-243.

Mast M, Mac Neil J, 1983. Effect of kosher VS conventional processing on yield quality and acceptability of broiler chickens. J Food Sci 48:1013-5.

Mormède $\mathrm{P}$, Andanson $\mathrm{S}$, Aupérin $\mathrm{B}$, Beerda B, Guémené D, Malmkvist J, Manteca X, Manteuffel G, Prunet P, van Reenen C.G, Richard S, Veissier I, 2007. Exploration of the hypothalamicpituitary-adrenal function as a tool to evaluate animal welfare. Physiol Behav 92:317-39.

Nakyinsige K, Sazili AQ, Zulkifli I, Gohc YM, Abu Bakar F, Sabowb AB, 2014. Influence of gas stunning and halal slaughter (no stunning) on rabbits' welfare indicators and meat quality. Meat Sci 98:701-8.

Önenç A, Kaya A, 2004. The effect of electrical stunning and percussive captive bolt stunning on meat quality of cattle processed by Turkish slaughter procedures. Meat Sci 66:809-15.

Pollard JC, Littlejohn RP, Asher GW, Pearse AJT, Stevenson-Barry JM,
McGregor SK, Manley TR, Duncan SJ, Sutton CM, Pollock KL, 2002. A comparison of biochemical and meat quality variables in red deer (Cervus elaphus) following either slaughter at pasture or killing at a deer slaughter plant. Meat Sci 60:85-94.

Pufpaff MK, 2014. Breaking down the barriers between halal slaughter and animal welfare. Arch Latinoam Prod Anim 22:375-8.

Qur'an. The Holy Koran; Arberry, A.J., Translator; TheWorld's Classics Paperback Edition. Oxford University Press: Oxford, UK, 1983.

Rahman SA, 2017. Religion and animal welfare - An Islamic perspective. Animals 7-11.

Regenstein JM, Chaudry MM, Regenstein CE, 2003. The kosher and halal food laws. Comprehens Rev Food Sci Food Saf 2:111-27.

Riaz MN, Chaudry MM, 2004. Halal food production. Boca Raton, FL: CRC Press (Publication).

Rosen SD, 2004. Physiological insights into Shechitàh. Faculty of Medicine, Imperial College, London. Vet Rec 154:759-65.

World Organization of Animal Health: OIE, 2013. Slaughter of animals. Terrestrial Animal Health Code. Chapter 7.5. 